\title{
Penentuan Waktu Baku Dalam Pengecekan Bonding Sampel Sepatu Pada PT. Ching Luh Indonesia
}

\section{Determine Standard Time For Shoes Bonding Sample Inspection At PT. Ching luh Indonesia}

\author{
Ossa Sutaarga ${ }^{1}$, Alfiandy Setiawan ${ }^{2}$ \\ 1,2. Program Studi Teknik Industri, Fakultas Teknik, Universitas Muhammadiyah Tangerang \\ 1ossa.sutaarga@gmail.com, ${ }^{2}$ alfiandysetiawan17@gmail.com,
}

\begin{abstract}
PT. Ching Luh Indonesia is a company engaged in the manufacturing industry that produces sports shoes with well-known global brands, with annual revenues of more than US \$1 billion, and has 8,000 workers. PT. Ching Luh Indonesia is a company that is responsive to technological advances and pays great attention to the comfort of employees in working, especially in the Laboratory section. In that section, the bonding checking process on the shoe samples currently still uses direct checking without any time reference in each sample. This is considered less effective because it makes the addition of the remaining sample for the next shift. This study aims to determine the standard time of each shoe sample variant and to determine the number of samples received by each operator. From the research results using the calculation of the standard time can be determined the standard time of each variant of the shoe sample, so it can also be determined the number of samples received for each operator. By determining the standard time for each shoe sample, it is expected that each operator can complete each sample according to the predetermined standard time, so that the specified target can be achieved..
\end{abstract}

Keywords: Standard Time, Bonding, Shoe Samples, Laboratory, Operator

\begin{abstract}
ABSTRAK
PT. Ching Luh Indonesia merupakan perusahaan yang bergerak di bidang industri manufaktur yang memproduksi sepatu olahraga dengan merk-merk global ternama, dengan pendapatan tahunan lebih dari US\$ 1 Milyar, dan mempunyai 8.000 pekerja. PT. Ching Luh Indonesia merupakan perusahaan yang tanggap akan kemajuan teknologi dan sangat memperhatikan kenyamanan pada karyawan dalam bekerja khususnya pada bagian Laboratorium. Pada bagian tersebut proses pengecekan bonding pada sampel sepatunya saat ini masih menggunakan pengecekan langsung tanpa adanya acuan waktu disetiap sampelnya. Hal tersebut dinilai kurang efektif karena membuat penambahan sampel sisa untuk shift selanjutnya. Penelitian ini bertujuan untuk dapat mengetahui waktu baku dari setiap varian sampel sepatu dan untuk menentukan jumlah sampel yang diterima setiap operator. Dari hasil penelitian dengan menggunakan perhitungan waktu baku dapat ditentukan waktu baku dari setiap varian sampel sepatu, sehingga dapat ditentukan pula jumlah sampel yang diterima untuk setiap operator. Dengan ditentukannya waktu baku dari setiap sampel sepatu, diharapkan agar setiap operator mampu menyelesaikan setiap sampel sesuai dengan waktu baku yang telah ditentukan, agar target yang ditentukan dapat tercapai.
\end{abstract}

Kata Kunci: Waktu Baku, Bonding, Sampel Sepatu, Laboratorium, Operator 


\section{PENDAHULUAN}

\subsection{Latar Belakang}

PT. Ching Luh Indonesia merupakan salah satu perusahaan yang memproduksi sepatu saat ini dengan brand Nike dan masih ada beberapa perusahaan yang memproduksi sepatu dengan brand Nike. Oleh karena itu, PT. Ching Luh Indonesia melakukan inovasiinovasi terhadap proses produksinya terutama pengecekan kualitasnya yang ada didalam Laboratorium. Dalam pengecekan kualitas pada sepatu ada beberapa metode pengujian yang dilakukan antara lain, Strip Bonding. Pull Test, Ply Adhesion, Flex Shoe, Compression Set dan masih banyak metode pengujian yang lain.

Dalam hal ini, pengujian dengan metode Strip Bonding menjadi fokus utama oleh Tim Laboratorium dalam pengujian kualitas sepatu. Strip Bonding sendiri bertujuan untuk menentukan kekuatan penempelan antara dua material. Dan dalam pengujian Strip Bonding ini dilakukan oleh operator laboratorium dengan menggunakan mesin Instron, namun dalam pengujian sampelnya masih belum ada waktu acuan atau waktu baku dari setiap model sepatu. Hal ini menyebabkan sering kali adanya beberapa sampel yang belum diselesaikan, sehingga menjadi sampel tambahan untuk shift selanjutnya. Perbandingan jumlah sampel yang harus dicapai dan sampel yang bisa dicapai dapat dilihat pada Gambar 1.1.

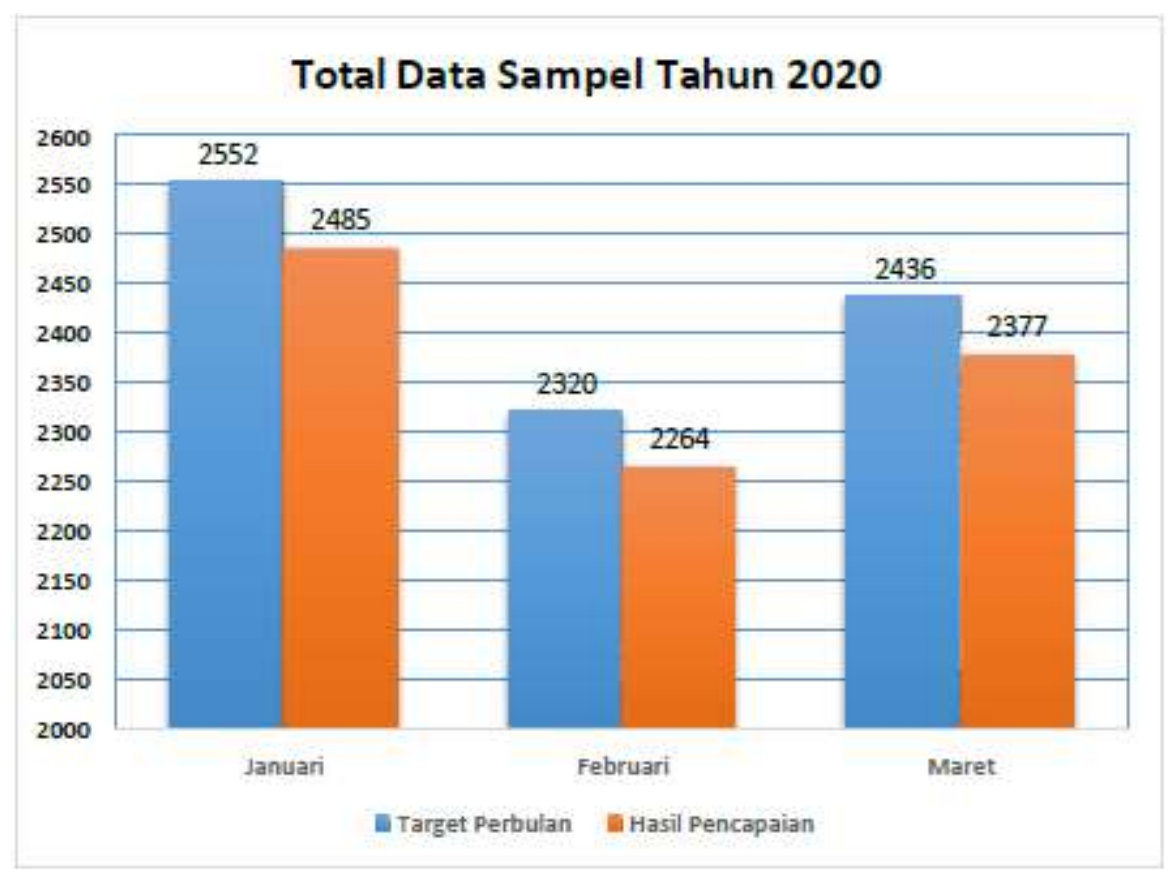

Gambar 1.1. Grafik Total Sampel Periode Januari-Maret 2020

Hal tersebut dinilai kurang efektif karena terjadi keterlambatan dari pengujian sampel harian, sedangkan jumlah sampel yang diuji dalam sehari adalah sebanyak 29 pasang atau 58 pieces, sehingga membuat bertambahnya sampel yang harus diuji untuk shift selanjutnya. Dengan penambahan sampel yang harus diuji oleh shift selanjutnya akan membuat target untuk shift selanjutnya juga tidak tercapai. Maka dari itu, laboratorium dari perusahaan saat ini membutuhkan perhitungan waktu baku dalam penyelesaian proses pengujian bonding sampel sepatu. Karena dengan adanya waktu baku proses didalam suatu perusahaan, maka lama waktu yang digunakan untuk menyelesaikan pengujian didalam suatu perusahaan bisa seragam dan sama. Perbedaan kapasitas setiap pekerja dalam menyelesaikan suatu pekerjaan menjadi salah satu kendala kerja dalam menyelesaikan 
target produksi yang dikehendaki perusahaan. Dari perbedaan kapasitas yang ada ini dapat menimbulkan munculnya kendala kerja.

Untuk mengatasi permasalahan yang telah dipaparkan sebelumnya maka penyusun melakukan penelitian usulan penentuan waktu baku dalam pengujian bonding pada sampel sepatu. Standar kerja yang baik harus ditetapkan dengan asumsi mampu memberikan motivasi kepada pegawai untuk bekerja dengan baik, dan juga pada tingkat dimana ratarata karyawan dapat mencapainya.

\section{METODOLOGI}

\subsection{Perhitungan Waktu Siklus}

Langkah ini merupakan langkah utama dalam pengukuran kerja, yaitu melakukan perhitungan waktu siklus pada tiap proses. Pengukuran waktu siklus diawali dengan mengambil sampel pekerjaan sebanyak 10 data waktu, yang kemudian ditentukan waktu pengerjaan setiap varian dengan menggunakan stopwatch. Setelah semua data telah dikumpulkan, barulah dapat ditentukan waktu siklusnya.

\subsection{Penentuan Waktu Normal Dengan Menghitung Nilai Penyesuaian}

Penulis mengamati kewajaran kerja yang ditunjukkan oleh pekerja ketidakwajaran dapat terjadi misalnya bekerja tanpa kesungguhan, sangat cepat seolah-olah dikejar oleh waktu atau karena menjumpai kesulitan-kesulitan seperti kondisi ruangan yang tidak mendukung untuk bekerja (Sutalaksana; dkk, 2006). Penyebab seperti tersebut mempengaruhi kecepatan kerja yang berakibat terlalu singkat atau terlalu panjangnya waktu penyelesaian. Hal ini jelas tidak diinginkan karena waktu standar yang dicari merupakan waktu yang diperoleh dari kondisi dan cara kerja yang mendukung seorang bekerja menyelesaikan suatu pekerjaan. Performance Rating didapatkan dari memperhitungkan jika operator bekerja dengan kecepatan tidak wajar, sehingga hasil pengukuran waktu perlu disesuaikan atau dinormalkan apabila:

a) Operator bekerja terlalu cepat (bekerja di atas batas normal) maka nilai $\mathrm{p}>1$ atau $\mathrm{p}=100 \%$.

b) Operator bekerja secara normal (bekerja secara wajar) maka nilai $\mathrm{p}=1$ atau $\mathrm{p}$ $=100 \%$. Bila operasi dilaksanakan penuh oleh mesin maka dianggap normal.

c) Operator bekerja terlalu lambat (bekerja di bawah batas normal) maka nilai $\mathrm{p}<$ 1 atau $\mathrm{p}<100 \%$. 
Tabel 2.1. Tabel Faktor Penyesuaian

\begin{tabular}{|c|c|c|c|}
\hline Faktor & Kelas & Lambang & Penyesuaian \\
\hline \multirow{11}{*}{ Keterampilan } & \multirow{2}{*}{ Superskill } & Al & +0.15 \\
\hline & & A2 & +0.13 \\
\hline & \multirow{2}{*}{ Excellent } & $\mathrm{BI}$ & +0.11 \\
\hline & & B2 & +0.08 \\
\hline & \multirow{2}{*}{ Good } & $\mathrm{Cl}$ & +0.06 \\
\hline & & $\mathrm{C} 2$ & +0.03 \\
\hline & Average & $\mathrm{D}$ & 0.00 \\
\hline & \multirow{2}{*}{ Fair } & El & -0.05 \\
\hline & & E2 & -0.10 \\
\hline & \multirow{2}{*}{ Poor } & $\mathrm{Fl}$ & -0.16 \\
\hline & & F2 & -0.22 \\
\hline \multirow{11}{*}{ Usaha } & \multirow{2}{*}{ Excessive } & $\mathrm{Al}$ & +0.13 \\
\hline & & A2 & +0.12 \\
\hline & \multirow{2}{*}{ Excellent } & $\mathrm{BI}$ & +0.10 \\
\hline & & B2 & +0.08 \\
\hline & \multirow{2}{*}{ Good } & $\mathrm{Cl}$ & +0.05 \\
\hline & & $\mathrm{C} 2$ & +0.02 \\
\hline & Average & $\mathrm{D}$ & 0.00 \\
\hline & \multirow{2}{*}{ Fair } & El & -0.04 \\
\hline & & E2 & -0.08 \\
\hline & \multirow{2}{*}{ Poor } & $\mathrm{Fl}$ & -0.12 \\
\hline & & $\mathrm{F} 2$ & -0.17 \\
\hline \multirow{6}{*}{ Kondisi } & Ideal & A & +0.06 \\
\hline & Excellent & $\mathrm{B}$ & +0.04 \\
\hline & Good & C & +0.02 \\
\hline & Average & D & 0.00 \\
\hline & Fair & $\mathrm{E}$ & -0.03 \\
\hline & Poor & $\mathrm{F}$ & -0.07 \\
\hline \multirow{6}{*}{ Konsistensi } & Ideal & A & +0.04 \\
\hline & Excellent & B & +0.03 \\
\hline & Good & C & +0.01 \\
\hline & Average & D & 0.00 \\
\hline & Fair & $\mathrm{E}$ & -0.02 \\
\hline & Poor & $\mathrm{F}$ & -0.04 \\
\hline
\end{tabular}

Sumber: Sutalaksana, dkk (20062.3 Menentukan Nilai Waktu Baku dengan nilai kelonggaran (Allowance)

Salah satu hal yang paling penting di perhatikan dalam pengukuran waktu adalah faktor kelonggaran. Faktor kelonggaran ini ditambahkan pada waktu normal yang telah didapatkan. Kelonggaran diberikan untuk tiga hal yaitu kebutuhan pribadi, menghilangkan rasa fatique dan hambatan-hambatan yang tidak dapat dihindarkan Ketiga hal ini merupakan hal yang secara nyata dibutuhkan oleh pekerja, dan yang selama pengukuran tidak diamati, diukur, dicatat, ataupun dihitung. Karenanya sesuai pengukuran dan setelah mendapatkan waktu normal, kelonggaran perlu ditambahkan. (Sutalaksana; dkk, 2006)

a) Kelonggaran untuk kebutuhan pribadi (personal allowance)

b) Kelonggaran untuk menghilangkan rasa lelah (Fatique Allowance)

c) Kelonggaran untuk hambatan-hambatan yang tak terhindarkan. 
Tabel 2.2. Tabel kelonggaran allowance

\begin{tabular}{|c|c|c|c|c|c|}
\hline \multicolumn{2}{|r|}{ Faktor } & \multicolumn{2}{|c|}{ Contoh Pekerjaan } & \multicolumn{2}{|c|}{ Kelonggaran } \\
\hline A. & Tenaga yang dikeltiarkan & & Ekivalen beban & Pria & Wanita \\
\hline 1. & Dapat diabaikan & Bekerja dimeja, duduk & Tanpa beban & $0,0-6,0$ & $0,0-6,0$ \\
\hline 2. & Sangat ringan & Bekerja dimeja, berdiri & $0,00-2,25$ & $6,0-7,5$ & $6,0-7,5$ \\
\hline 3. & Ringan & Menyekop, ringan & $2,25-9,00$ & $7,5-12,0$ & $7,5-16,0$ \\
\hline 4. & Sedang & Mencangkul & $9.00-18,00$ & $12,0-19,0$ & $16,0-30,0$ \\
\hline 5. & Berat & $\begin{array}{l}\text { Mengayun palu yang } \\
\text { berat }\end{array}$ & $19,00-27,00$ & $19,00-30,00$ & \\
\hline 6. & Sangat berat & Memanggul beban & $27,00-50,00$ & $30,00-50,00$ & \\
\hline 7. & Luar biasa berat & Memanggul karung berat & Diatas $50 \mathrm{~kg}$ & & \\
\hline $\begin{array}{l}\text { B. } \\
1 .\end{array}$ & $\begin{array}{l}\text { Sikap kerja } \\
\text { Duduk }\end{array}$ & Bekerja duduk. ningan & & 0.0 & \\
\hline 2. & Berdiri di atas dua kaki & $\begin{array}{l}\text { Badan tegak, ditumpu } \\
\text { dua kaki }\end{array}$ & & & \\
\hline 3. & Berdiri di atas satu kaki & $\begin{array}{l}\text { Satu kaki mengerjakan } \\
\text { alat kontrol }\end{array}$ & & & \\
\hline 4. & Berbaring & Pada bagian sisi, belakang & au depan badan & & \\
\hline 5. & Membungkuk & $\begin{array}{l}\text { Badan dibungkukkan bertu } \\
\text { kaki }\end{array}$ & pu pada kedua & & \\
\hline c. & Gerakan kerja & & & & \\
\hline 1. & Normal & Ayunan bebas dari palu & & & \\
\hline 2. & Agak terbatas & Ayunan terbatas dari palu & & & \\
\hline 3. & Sulit & Membawa beban berat den & an satu tangan: & & \\
\hline 4. & $\begin{array}{l}\text { Pada anggota-anggota } \\
\text { badan terbatas }\end{array}$ & Bekerja dengan tangan di a & is kepala & & \\
\hline 5. & $\begin{array}{l}\text { Seluruh anggota budan } \\
\text { terbatas }\end{array}$ & Bekerja dilorong pertamba & gan yang sempit & & \\
\hline D. & Kelelahan mata *) & & & $\begin{array}{l}\text { Pencahayaan } \\
\text { baik }\end{array}$ & $\begin{array}{c}\text { Pencahayaan } \\
\text { buruk }\end{array}$ \\
\hline 1. & $\begin{array}{l}\text { Pandangan yang terputus- } \\
\text { putus }\end{array}$ & Membawa alat ukur & & $0,0-6,0$ & $0,0-6,0$ \\
\hline 2. & $\begin{array}{l}\text { Pandangan yang hampir teru } \\
\text { menerus }\end{array}$ & Pekerjaan-pekerjaan y & ng teliti & $6,0-7.5$ & $6,0-7,5$ \\
\hline 3. & $\begin{array}{l}\text { Pandangan terus menerus } \\
\text { dengan fokus tetap }\end{array}$ & Pemeriksaan yang san & at teliti & $7,5-12,0$ & $7.5-16,0$ \\
\hline 4 & $\begin{array}{l}\text { Pandangan terus menerus } \\
\text { dengan fokus berubah-ubah }\end{array}$ & Memeriksa cacat pads & tain & $12,0-19,0$ & $16,0-30,0$ \\
\hline 5. & $\begin{array}{l}\text { Pandangan terus menerus } \\
\text { dengan konsentrasi tinggi da } \\
\text { fokus tetap. }\end{array}$ & & & $19,0-30,0$ & \\
\hline 6. & $\begin{array}{l}\text { Pandangan terus menerus } \\
\text { dengan konsentrasi tinggi da } \\
\text { fokus berubah }\end{array}$ & & & $30,0-50,0$ & \\
\hline
\end{tabular}

Sumber : Sutalaksana, dkk (2006)

\section{HASIL DAN PEMBAHASAN \\ 3.1 Menghitung Waktu Siklus}

Tabel 3.1 Waktu Siklus setiap tipe Produk

\begin{tabular}{|c|c|c|c|c|c|c|c|c|c|c|c|}
\hline \multirow{2}{*}{ Varian Sepatu } & \multicolumn{7}{|c|}{ Pengujian (menit) } & \multirow{2}{*}{ EXi } \\
\cline { 2 - 11 } & $\mathbf{1}$ & $\mathbf{2}$ & $\mathbf{3}$ & $\mathbf{4}$ & $\mathbf{5}$ & $\mathbf{6}$ & $\mathbf{7}$ & $\mathbf{8}$ & $\mathbf{9}$ & $\mathbf{1 0}$ & \\
\hline Nike Tanjun & 15,20 & 16,12 & 15,40 & 16,27 & 16,14 & 15,55 & 15,28 & 15,47 & 15,33 & 16,03 & 155,89 \\
\hline $\begin{array}{c}\text { Nike Revolution 4 } \\
49,32\end{array}$ & 49,41 & 48,43 & 49,12 & 48,53 & 48,37 & 49,09 & 48,47 & 49,16 & 49,02 & 488,92 \\
\hline $\begin{array}{c}\text { Nike Revolution 4 } \\
\text { GS }\end{array}$ & 47,20 & 47,32 & 48,17 & 48,03 & 47,51 & 47,47 & 47,56 & 48,10 & 47,52 & 48,01 & 476,89 \\
\hline $\begin{array}{c}\text { Nike Revolution 5 } \\
\text { Nike Revolution 5 } \\
\text { GS }\end{array}$ & 46,56 & 46,47 & 47,12 & 47,38 & 47,29 & 46,5 & 46,39 & 46,44 & 47,13 & 47,15 & 468,43 \\
\hline
\end{tabular}

(sumber : data diolah oleh penulis) 
Menghitung waktu baku dari total waktu siklus setiap varian dengan rumus, sbb :

$$
\begin{aligned}
& W s=\frac{\sum X i}{N} \\
& W s=\frac{155,89}{10} \\
& W s=15,59 \text { menit }
\end{aligned}
$$

Dari perhitungan waktu siklus semua varian diatas maka didapat hasil sebagai berikut :

\begin{tabular}{|l|c|}
\hline \multicolumn{1}{|c|}{ Varian Sepatu } & Waktu Siklus \\
\hline Nike Tanjun & 15.59 \\
\hline Nike Revolution 4 & 48.89 \\
\hline Nike Revolution 4 GS & 47.69 \\
\hline Nike Revolution 5 & 46.84 \\
\hline Nike Revolution 5 GS & 46.75 \\
\hline
\end{tabular}

(sumber : data diolah oleh penulis)

\subsection{Menentukan Waktu Normal Dengan Menghitung Faktor Penyesuaian} Tabel 3.2 Tabel Nilai Faktor Penyesuaian

\begin{tabular}{|l|l|l|l|}
\hline Faktor & Kelas & Lambang & Penyesuaian \\
\hline Keterampilan & Excellent & B2 & +0.08 \\
\hline Usaha & Good & C1 & +0.05 \\
\hline Kondisi Kerja & Excellent & B & +0.04 \\
\hline Konsistensi & Good & C & +0.01 \\
\hline TOTAL & & +0.18 \\
\hline
\end{tabular}

Didapatkan nilai faktor penyesuaian dengan menggunakan metode Westinghouse adalah $\mathrm{p}=1+0,18=1,18$.

$$
\begin{aligned}
& W n=W s \times p \\
& W n=15.59 \times 1.18 \\
& W n=18.40
\end{aligned}
$$

\begin{tabular}{|l|c|c|}
\hline \multicolumn{1}{|c|}{ Varian Sepatu } & Waktu Siklus & Waktu Normal \\
\hline Nike Tanjun & 15.59 & 18.40 \\
\hline Nike Revolution 4 & 48.89 & 57.69 \\
\hline Nike Revolution 4 GS & 47.69 & 56.27 \\
\hline Nike Revolution 5 & 46.84 & 55.27 \\
\hline Nike Revolution 5 GS & 46.75 & 55.17 \\
\hline
\end{tabular}

\subsection{Menentukan Nilai Waktu Baku dengan nilai kelonggaran (Allowance)}


Tabel 3.3 Nilai Allowance

\begin{tabular}{|c|l|c|}
\hline No. & \multicolumn{1}{|c|}{ Faktor } & Kelonggaran (\%) \\
\hline B-1 & Duduk & 1,0 \\
\hline C-1 & Normal & 0 \\
\hline D-3 & Pandangan terus menerus dengan fokus tetap & 9,0 \\
\hline E-4 & Normal & 5,0 \\
\hline F-1 & Baik & 0 \\
\hline G-1 & $\begin{array}{l}\text { Bersih, sehat, cerah dengan kadar kebisingan } \\
\text { rendah }\end{array}$ & 0 \\
\hline Kelonggaran Kebutuhan Pribadi & 2,0 \\
\hline \multicolumn{2}{|c|}{ a $=$} & $17 \%$ atau 0,17 \\
\hline
\end{tabular}

$W b=W n x(1+a)$

$W b=18.40 \times(1+0.17)$

$W b=21.53$

Tabel 3.4 Total Perhitungan Waktu Baku

\begin{tabular}{|l|c|c|c|}
\hline \multicolumn{1}{|c|}{ Varian Sepatu } & Waktu Siklus & Waktu Normal & Waktu Baku \\
\hline Nike Tanjun & 15.59 & 18.40 & 21.53 \\
\hline Nike Revolution 4 & 48.89 & 57.69 & 67.50 \\
\hline Nike Revolution 4 GS & 47.69 & 56.27 & 65.84 \\
\hline Nike Revolution 5 & 46.84 & 55.27 & 64.67 \\
\hline Nike Revolution 5 GS & 46.75 & 55.17 & 64.55 \\
\hline
\end{tabular}

\section{SIMPULAN DAN SARAN}

4.1 Nilai Waktu Baku dari setiap varian sepatu dalam pengujian bonding adalah sebagai berikut:

a. Varian Nike Tanjun adalah 21,53 menit

b. Varian Nike Revolution 4 adalah 67,50 menit

c. Varian Nike Revolution 4 GS adalah 65,84 menit

d. Varian Nike Revolution 5 adalah 64,67 menit

e. Varian Nike Revolution 5 GS adalah 64,55 menit.

4.2 Setelah waktu baku diketahui, dapat ditentukan jumlah sampel per operator untuk dilakukan pengecekan adalah sebagai berikut 
Tabel 4.1 Penentuan Jumlah Sampel yang dikerjakan dalam 1 hari tiap operator

\begin{tabular}{|l|c|c|c|c|c|c|c|}
\hline \multirow{2}{*}{\multicolumn{1}{|c|}{ Varian }} & \multicolumn{7}{|c|}{ Jumlah pieces per Varian } \\
\cline { 2 - 9 } & $\mathbf{1}$ & $\mathbf{2}$ & $\mathbf{3}$ & $\mathbf{4}$ & $\mathbf{5}$ & $\mathbf{6}$ & $\mathbf{7}$ \\
\hline Nike Tanjun & 4 & 3 & 1 & - & 3 & - & 1 \\
\hline Nike Revohution 4 & - & 2 & - & 2 & 2 & 2 & - \\
\hline Nike Revohution 4 GS & 2 & 2 & 2 & 2 & 1 & 1 & 2 \\
\hline Nike Revohution 5 & 2 & 2 & 3 & 1 & 1 & 2 & 3 \\
\hline Nike Revohution 5 GS & 2 & - & 2 & 2 & 2 & 2 & 2 \\
\hline TOTAL PIECES & $\mathbf{1 0}$ & 9 & $\mathbf{8}$ & 7 & 9 & 7 & $\mathbf{8}$ \\
\hline TOTAL WAKTU & $\mathbf{4 7 6 , 2 4}$ & $\mathbf{4 6 0 , 6 1}$ & $\mathbf{4 7 6 , 3 2}$ & $\mathbf{4 6 0 , 4 5}$ & $\mathbf{4 5 9 , 2 0}$ & $\mathbf{4 5 9 , 2 8}$ & $\mathbf{4 7 6 , 3 2}$ \\
\hline $\begin{array}{l}\text { TOTAL WAKTU } \\
\text { KERJA DALAM 1 } \\
\text { SHIFT }\end{array}$ & & 8 jam / 480 menit & & \\
\hline
\end{tabular}

\section{DAFTAR PUSTAKA}

Afiani, R., \& Pujotomo, D. (2017). Penentuan Waktu Baku dengan Metode Stopwatch Time Study Studi Kasus CV. MANS Group, Industrial Engineering Online Journal, 6(1).

Amri, A. (2014). Bahan Ajar Pengantar Teknik Industri. Aceh: Universitas Malikussaleh.

Ciptani, M. K. (2001). Peningkatan Produktivitas Dan Efisiensi Biaya Melalui Integrasi Time \& Motion Study Dan Activity-Based Costing, Jurnal Akuntansi dan Keuangan, 3(1), 30-50.

Erliana, C. I. (2015). Bahan Ajar Analisa dan Pengukuran Kerja. Aceh: Jurusan Teknik Industri Fakultas Teknik Universitas Malikussaleh.

Kumar, S.A., (2006). Production and Operation Management. New Delhi: New Age International (P) Ltd.

Putranti, K. A., Herodian, S., \& Syuaib, M. F. (2012). Studi Waktu (Time Study) Pada Aktivitas Pemanenan Kelapa Sawit di Perkebunan Sari Lembah Subur, Riau. Skripsi. Jurusan Teknologi Pertanian IPB, Bogor.

Sutalaksana, I. Z., Anggawisastra, R., \& Tjakraatmadja, J. H. (2006). Teknik Perancangan Sistem Kerja. Bandung: ITB.

Zuriwiatma, M., Ushada, M., \& Mulyati, G. T. (2014). Analysis of Capacity Constrained Worker Using Time Study, Heart Rate and Profile of Mood States (Case Study of Tempe Industry "Muchlar" Kasihan Bantul). Agritech, Vol. 34, No. 3, Agustus 2014 